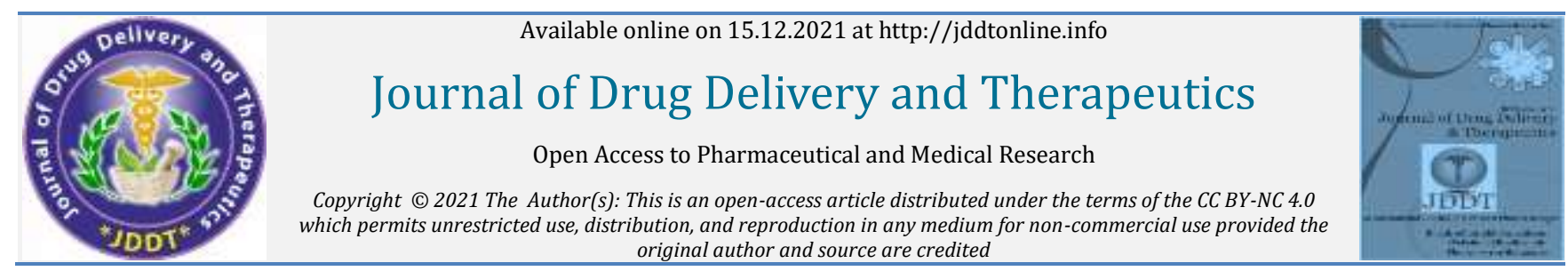

Open Access Full Text Article original author and source are credited

Review Article

\title{
Misuse of Antibiotic during COVID 19 Outbreaks
}

\author{
Vinoth Rajendran ${ }^{*}$, Sambath Kumar R. ${ }^{2 *}$ (ii), Venkateswaramurthy N. ${ }^{\text {(ii }}$ \\ ${ }^{1}$ Post Graduate Student, Department of Pharmacy Practice, J.K.K. Nattraja College of Pharmacy, Namakkal (Dt), Kumarapalayam- 638 183, Tamil \\ Nadu, India. \\ 2 Professor and Head, Department of Pharmaceutics, J.K.K. Nattraja College of Pharmacy, Namakkal (Dt), Kumarapalayam- 638 183, Tamil Nadu, \\ India. \\ ${ }^{3}$ Professor and Head, Department of Pharmacy Practice, J.K.K. Nattraja College of Pharmacy, Namakkal (Dt), Kumarapalayam- 638 183, Tamil \\ Nadu, India.
}

\section{Article Info:}

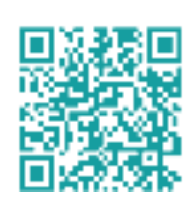

Article History:

Received 10 October 2021 Reviewed 17 November 2021 Accepted 23 November 2021

Published 15 December 2021

\section{Cite this article as:}

Vinoth R, Sambath Kumar R, Venkateswaramurthy N, Misuse of Antibiotic during COVID 19 Outbreaks, Journal of Drug Delivery and Therapeutics. 2021; 11(6-S):181-187

DOI: http://dx.doi.org/10.22270/jddt.v11i6-S.5102

*Address for Correspondence:

Vinoth Rajendran, Post graduate Student, Department of Pharmacy Practice, J.K.K Nattraja College of Pharmacy, Kumarapalayam- 638183, Tamilnadu, India.

\section{Abstract}

The COVID-19 outbreak, caused by the severe acute respiratory syndrome coronavirus 2 , has been detected in December 2019 in Wuhan, China, and is accompanied by significant degrees of morbidity and mortality. Antibiotic resistance (AMR) threatens to wreak havoc on healthcare system and the impact of globalization, and COVID-19 is intended to keep it at bay for the time being. During the COVID-19 crisis, a wide range of antimicrobial medicines were promoted as viable treatments. While both industrialized and industrializing nations have seen a rise in antimicrobial medication usage, use and abuse have been significantly more prevalent in developing countries. Antibiotic resistance is still a concern since microorganisms that cause resistant infections develop in hospitals and medical institutions, placing all patients at risk, complicating the care of COVID-19. Improper prescriptions, a lack of care management policies and needless self-administration by the general population are examples of these. Antibiotics seem to be more motivated to abuse and misusing antibiotics than to keep them safe and take them only when prescribed. Almost all of the substantial antibiotic usage in COVID-19 patients is inevitable. Patients having lung viral infections are more likely to develop subsequent bacterial infections, which lead to higher disease severity and death. Immediately crucial components of any AMR mitigation approach are increased spending in education and increased public knowledge of AMR. More studies are needed to better understand the health risks and rate of co-infection in COVID-19 patients in order to promote a decrease in any unnecessary antimicrobial prescribing.

Keywords: COVID-19; Antibiotic use and misuse; Antimicrobial Resistance.

\section{INTRODUCTION:}

Coronaviruses (CoVs) have been linked to severe disease outbreaks in East Asia and the Middle East during the last two decades. The Middle East respiratory syndrome (MERS) and the severe acute respiratory syndrome (SARS) first appeared in 2002 and 2012, respectively. In late 2019, a new coronavirus, severe acute respiratory syndrome coronavirus 2 (SARS-CoV-2), which causes coronavirus disease 2019 (COVID-19), appeared, posing a worldwide health hazard and generating an ongoing pandemic in numerous nations and territories ${ }^{1}$. The World Health Organization (WHO) has named the current CoV-related disease COVID-19, which is caused by SARS-CoV-2. The main cluster of diseases has been shown to be linked to Wuhan's Huanan South Chinese seafood market ${ }^{2}$. The corona virus, which belongs to the corona virus family, is primarily responsible for the illness. These members of the family are single-stranded, positively sensitive RNA viruses that cause mild respiratory infections in humans. However, in some circumstances, they can cause major difficulties in the central nervous system, gastrointestinal tract, and respiratory system ${ }^{3,4}$. This hidden illness is antimicrobial resistance (AMR), which is aggravated by antibiotics. There is no such thing as a vacuum when it comes to the discovery of novel therapeutic antibiotics ${ }^{5,6}$. Immunocompromised patients who have already been infected with a respiratory infection, such as $\mathrm{TB}$, influenza, acute respiratory syndrome (SARS), or presently covid-19, are at a higher risk of getting serious illnesses $^{7}$. The spread of SARS-CoV-2 is quite troubling because it has the potential to be very severe in low- and middle-income nations (LMICs), Antibiotics help lower morbidity and death linked with infectious illnesses in underdeveloped nations where health remains poor ${ }^{8,9}$. As the globe responds to COVID-19, a major underlying threat of antimicrobial resistance (AMR) lurks. It was already killing hundreds of thousands of people worldwide at the time (approximately 700000 deaths per year). The widespread and inappropriate use of antibiotics, among other factors, aided in the formation and dissemination of anti-pathogens 10-12. Unfortunately, microorganisms developed resistance to existing antibiotics within a few years after their introduction. Fungus has generated an equivalent level of resistance ${ }^{13}$. There has been a lack of systematic measures to minimise AMR, resulting in millions of fatalities worldwide and on a yearly basis AMR has the potential to become a 
more frequent component by 2050. Death is more common than cancer ${ }^{14}$. AMR is frequently a major cause of death in developing countries due to a lack of exposure to the most economical and efficient antibiotics ${ }^{15}$. COVID-19 poses issues in all aspects of health care, including the management of chronic illnesses and non-covid-19 severe bacterial infections ${ }^{16}$. Health-care systems are agitated, Implement anti-infective policies by isolating infected COVID-19 patients effectively in order to limit the virus's spread 17 . Antibiotics may be prescribed to COVID-19 patients for a number of reasons. Influenza patients have a higher death rate due to bacterial superinfection ${ }^{18}$. The widespread use of antibiotics raises concerns about overuse, which can convert into Antimicrobials and the development of a plethora of medications creatures that already exist by 2050, it is anticipated to be the leading cause of mortality worldwide ${ }^{19}$. Antibiotic prophylaxis, for example azithromycin may play a role in the progression of drug-resistant strains of Salmonella typhi ${ }^{20}$. In the setting of COVID-19 in undeveloped countries, there are also various relevant variables coming from the general population that encourage the development of antibiotic resistance.

Improper prescriptions, a lack of care management policies, and needless self-administration by the general population are examples of these. However, challenges in differentiating between Pneumonia caused by a bacterial infection and COVID-19 infection, as well as a paucity of antiviral medication with proven success, requires the use of antibiotics as part of the experience. The treatment plan for COVID-19 patients is critical ill ${ }^{21}$. The goal of this study was to consolidate information about the collateral effect of the COVID-19 pandemic on AMR containment based on the limited evidence that was available at the time. Our goals are to: share current understanding on the onset of the SARSCoV-2 and COVID-19 pandemics, and emphasise the potential role of the COVID-19 pandemic to the ongoing development and spread of AMR. In this paper, we examine the influence of the present COVID-19 pandemic on the danger of AMR, focusing on the relationship of bacterial coinfections in COVID-19 patients.

\section{INADEQUATE SUPERVISION IMPLEMENTATION:}

AND

Antimicrobial dispensing is controlled in developed nations, and medication is normally necessary. However, the ability to buy antimicrobials online has made them more widely available in wealthy countries ${ }^{9},{ }^{22}$. Antibiotics are widely available in many underdeveloped countries, can be obtained from street vendors and are available without a prescription. In the absence of this control, antibiotics are readily available and accessible, promoting self-medication and incorrect dosing 23 . Regulations are connected with inadequate drug monitoring systems, which manifest as incorrect selection, usage, and storage practices, allowing bacteria to evolve and spread resistance 24 .

\section{THE INFLUENCE OF COVID-19 ON ANTI- MICROBIAL RESISTANCE:}

Three factors influence the progression of AMR in a population: emergence, transmission, and population-level infections load. AMR is caused by selection pressures in the microbial community in people, animals, or the surroundings. Such selection forces, which are subject to the 'medicine and error' of anxiousness, promote antiacquisition techniques such as point mutation or horizontal gene transfer. Antibiotic resistance to one or more encryption methods ${ }^{25}$. Environmental factors and behaviours can allow or prevent the spread of these newly developed antimicrobial organisms (AROs) in humans, animals and habitats. The burden of ARO-related diseases will therefore be determined by the quantity and character of infections, as well as the availability, efficacy, and safety of alternate therapies. COVID-19 has the ability to alter all three of these components directly or indirectly as a result of pandemic response. The actions implemented by the government to the general population was advised to combat COVID19 have differed, but also include a combination of internal and external immigration restrictions; school, workplace, and non-essential service cancellations, the use of telehealth increased, physical distance measures; and mask wearing Although comfortable for both patients and physicians, one of the biggest reasons of antibiotic overuse is a lack of physical examination by healthcare providers and the lack of laboratory markers for identifying the seriousness of the ailment ${ }^{26}$.

\section{ANTIMICROBIAL RESISTANCE: A THREAT HIDING IN THE SHADOWS OF THE COVID-19 PANDEMIC:}

Increased antimicrobial usage is strongly linked to the establishment of worldwide AMR ${ }^{27}$. In many nations, certain patients demand for antimicrobials, while others seem to be more motivated to abuse and misusing antibiotics than to keep them safe and take them only when prescribed. Patients in impoverished nations frequently self-medicate because they believe public hospitals are overloaded or would impose larger financial obligations, or they merely give antimicrobials to test whether they improve. As a result, the high prevalence of patients seeking antimicrobials directly can have a significant influence on antimicrobial consumption and resistance development ${ }^{28}$. Furthermore, medicine quality suffers as a result of improper storage facilities, age, and the presence of none, too few, or too much active component. This might be deliberate or the result of bad production procedures. Inactive "excipients" in pharmaceuticals that have been adulterated can also be toxic to persons who ingest them. China and India have the unpleasant distinction of being the primary suppliers of counterfeit pharmaceuticals ${ }^{29}$. Drugs in higher-level health centres in India are less prone to be outdated, but many rural clinics give out-of-date medications, particularly in areas plagued by violence ${ }^{30}$. Patients' conditions worsens because the treatments contain a sub-therapeutic amount of the active component, which is inefficient in treating infections yet, the sub-optimal level leads to the establishment of tolerance ${ }^{31}$.

\section{THE IMPACT OF DRUG RESISTANCE IN COVID-} 19:

Individualized management and global infection control programmes both prioritise observing and researching the prevalence, causes, and transmission of $\mathrm{AMR}^{32}$. In relation to COVID-19 patients, 72 percent of patients reported hospitalisation for antimicrobial therapy ${ }^{33}$. In contrast, every time an antibiotic is taken, whether logically or irrationally, the genetic selection exerted leads to the selection of resistance microorganisms. Resistant microbes can survive in a host for minimum a year after choosing 34 . COVID-19 poses significant problems for many areas of health care, including infection, bacterial diagnosis and management, as well as drug administration. Recognizing that patients with viral pneumonia, such as COVID-19, are at higher risk of developing serious secondary bacterial infections, there is no denying that antibiotics are empirically recommended for many COVID-19 patients, especially in frequently agitated environments. In reality, according to a 
latest report, antiviral drugs and antibiotics were utilized by 93 percent and 100 percent of ICU and non-ICU patients, respectively 35 . Aside from the increased demand on healthcare situations and hospitals, knowledge on the usage of drugs to treat COVID-19 infection is freely open to the public on the internet. The lack of adequate knowledge of the significance of antibiotics, combined with the fear of COVID19 infection, has had a direct effect on increasing exposure to over-the-counter antibiotics, especially in low- and middle countries with impoverished antibiotic control strategies and limited access to health settings ${ }^{36}$.

\section{IN THE PRESENT COVID-19 PANDEMIC, THERE ARE SIGNS OF ANTIMICROBIAL ABUSE AND MISUSE:}

Antimicrobial agent therapy is used to treat bacterial or fungal respiratory infections that are indicated or proven. This might be empirical or specific in individuals diagnosed to hospitals, or it could be used to control nosocomial infections encountered while hospitalisation, such as hospital acquired pneumonia or ventilator-associated pneumonia ${ }^{37}$. Only minority patients may require antibiotic therapy, as a result, medications, particularly antibiotic, may be misused. Various investigations demonstrated that antimicrobial treatments were widely used as part of medical care plan for hospitalised COVID19 patients in some countries $^{37}, 38$. Whereas it implies that antibiotics or antivirals should be used in hospitalised COVID-19 patient populations with secondary bacterial infection, 19 the chance of antibiotic prescribing in a large number of patients without confirmed secondary infection is significantly increased, potentially leading to an increase in AMR through driving selection of multidrug resistant (MDR) organisms ${ }^{39}$. A retrospective study of 191 people from two local hospitals in Wuhan, China, found that 181 (95\%) had received antibiotics and 41 (21\%) had received antivirals ${ }^{37}$. One cohort study of 37 hospitalized patients in three medical centres in Wuhan reveals that $36(97.3 \%)$ got antiviral therapy, $29(78.5 \%)$ got probiotics, $28(75.7 \%)$ got managed with traditional Systems of medicine, and 22 (59.5\%) got antibiotics ${ }^{40}$. Throughout this aspect, it was revealed 68.9 percent of COVID-19 patients previously taken antibiotics (mainly azithromycin and ceftriaxone) prior to hospital admission, with a self-medication rate of 33.0 percent ${ }^{41}$. In a Wuhan investigation, 11 percent of 99 patients died, and 71 percent were given antibiotics; nevertheless, only 1 percent had co-infection with bacteria, and 4 percent had fungal coinfections ${ }^{42}$. Furthermore, in a single-centre research in Wuhan including 36 non-survivors with COVID-19, antimicrobial treatment was delivered to every patients, and 61.1 percent of these people got combination antibiotic medication, while 38.9 percent underwent single antibiotic ${ }^{34}$. Chen et al. found similar results, showing that 71 percent of patients got preventative therapy, with 45 percent of them receiving combination medication as a preventive measure for common illnesses. Microorganisms grow in just $1 \%$ of patients, including Klebsiella pneumoniae, Acinetobacter baumannii, and Aspergillus flavus isolated in one case, the investigation also revealed that this $A$. baumannii had a strong resistance to antimicrobials ${ }^{43}$. Antibiotics inefficacy may potentially be associated to bacterial resistance, while it is possible also that beginning and length of antibiotic therapy in each patient, as well as associated co-morbidities, had a substantial effect on the outcomes. Similarly, Clancy et al. discovered in a meta-analysis showed microbial lung superinfections were the cause of mortality in $32 \%$ of COVID-19-positive individuals worldwide. The investigators also demonstrated that 79 percent of patients were managed with antibacterial drugs, with A. baumannii, P. aeruginosa, K. pneumoniae, E. coli, and S. aureus being the most common causative agents ${ }^{44}$. Additionally, a retrospective research of 918 COVID-19 patients in Wuhan, China found that 7.1 percent of inpatients had a pathogens co-infection, including pneumonia (32.3 percent), bacteremia (24.6 percent), and urinary tract infections (21.5 percent) being the most common $^{45}$. One assessment of scientific literature on hospitalised COVID-19 patients report that while 72 percent $(1450 / 2010)$ got antibiotics, only 8 percent $(62 / 806)$ had recurrent microbial or fungal co-infections ${ }^{46}$. Many of the pathogens often detected in secondary bacterial infections, such as Staphylococcus aureus, Streptococcus pneumoniae, Neisseria meningitides, Haemophilus influenzae, Klebsiella pneumoniae, and members of the genera Proteus, Enterobacter, and Citrobacter spp., are found in hospitals ${ }^{47}$. Previous research also reveals that drug-resistant microorganisms, such as multidrug-resistant Escherichia coli, Enterococcus, Chlamydia pneumoniae, Klebsiella pneumonia, Pseudomonas aeruginosa, Mycoplasma pneumonia, and extended-spectrum beta-lactamase, promote some illnesses in COVID-19 patients $45,48,49$. Azithromycin, a broad-spectrum macrolide antibiotic used mostly to treat respiratory, gastrointestinal, and sexually contagious infectious diseases caused by a wide variety of extra- and intracellular bacteria ${ }^{50}$, will be mass-administered for control of COVID-19 excessive usage of azithromycin, a first-line antibiotic in the treatment of pneumonia, in COVID19 sick people will almost certainly result in prolonged selection of resistant bacteria, as well as greater resistance not only to the above antimicrobials but also to the macrolide family of drugs more broadly, and, through co selection due to the fact that resistance genes are frequently undertaken together on multidrug resistance plasmids, to other antibiotic families within the patient population ${ }^{51}$.

\section{ANTIBIOTIC RESISTANT DEVELOPMENT IN HOSPITALS:}

\section{Species of Candida:}

Species of Candida Several fungal infection were studied during the COVID-19 pandemic, however the advent of a novel multi-drug resistant Candida species has been linked to COVID-19 related candidiasis. The development of a novel Candida species is quite worrying, particularly given the prevalence of antibiotic resistance ${ }^{52}$. It is not understood how Candida produces co-infections among COVID-19 patients. Moreover, both Candida and SARSCoV-2 have been identified on same hospital surfaces, and COVID-19 diagnosed ICU patients have same health risks, medicines, and associated co-morbidities of C. Auris. The prevalence of multi-drug resistant C. Auris is already higher in developing world. Chowdhary A. et al. hypothesise that this is related to a higher global impact of C. Auris in underdeveloped nations because to limited diagnostic techniques and insufficient funding for infection prevention and control. Overloaded medical institutions in underdeveloped countries are unable to diagnose other infections, such as C. Auris, because they are focusing all of their limited diagnostic skills on SARS$\mathrm{CoV}-2$. As a result, the issue of multi-drug resistant C. Auris and possible epidemics is far more serious in impoverished nations than in industrialised countries ${ }^{53}$.

\section{New Delhi Metallo-Beta-Lactamase-Producing Carbapenem-Resistant Enterobacterales (NDM-CRE):}

New Delhi Metallo-Beta-Lactamase-Producing CarbapenemResistant Enterobacterales is one of the already identified possible etiological agent of healthcare-acquired infections in many countries, including developed nations such as Italy ${ }^{54}$. The majority of first-line treatment medicines seem to be 
ineffective against Enterobacterales species $^{55}$. COVID-19 individuals who had already been colonised with NDM-CRE or who developed it during their hospitalisation had an extended hospitalisation due to related comorbidities and antibiotic resistance ${ }^{54}$.

\section{Carbapenemase-Producing Enterobacterales (CPE):}

Carbapenemase-producing enterobacterales (CPE) have resurfaced in the aftermath of the COVID-19 outbreak, owing to careless antibiotic prescribing and a paucity of drug safety. The re-emergence of CPE and superinfection in COVID-19 patients is caused by a number of reasons. The most prevalent element in the therapy of COVID-19 patients is the use of immunomodulators such as corticosteroids. Severe lung damage and subsequent mechanical ventilation are also concerns ${ }^{56}$.

\section{Carbapenem-Resistant Acinetobacter Baumannii (CRAB):}

Hospital acquired Acinetobacter Baumannii strains have been associated with elevated in fatality in COVID-19 patients ${ }^{57}$. These pathogens were shown to be resistant to ciprofloxacin and gentamicin, resulting in higher morbidity and death in COVID-19 patients ${ }^{56}$.

\section{ANTIBIOTIC USAGE:}

Almost all of the substantial antibiotic usage in COVID-19 patients is inevitable. More studies are needed to better understand the health risks and rate of co-infection in COVID-19 patients in order to promote a decrease in any unnecessary antimicrobial prescribing. More studies are needed to better understand the health risks and rate of coinfection in COVID-19 patients in order to promote a decrease in any unnecessary antimicrobial prescribing. Azithromycin is an existing medicine that has been utilized for the present pandemic while new Coronavirus therapies are discovered. Several studies, warned against taking azithromycin except in the treatment of community acquired pneumonia (CAP), stating that there is no clear evidence that azithromycin may have therapeutic benefits in COVID-19 other than antibacterial properties in bacterial superinfection ${ }^{58}$. It is also suggested that some antibacterial, such as teicoplanin (a glycopeptide antibiotic), might be effective against COVID-19 after previously demonstrating antiviral efficacy towards coronaviruses 59 . According to a group of European doctors, it can be hard to identify COVID19 from bacterial pneumonia, which implies that antibiotics are being given to people who do not have bacterial infections ${ }^{39}$. COVID-19 is becoming more common in Low Middle Income Countries (LMICs), presenting severe concerns given the poor healthcare systems, limited knowledge, and insufficient readiness for outbreaks in most of these countries. A big COVID-19 pandemic might amplify the rise in AMR in LMICS60. Because it is hard to distinguish among bacterial and viral pneumonia, the Infectious Disease Society of America (IDSA) guideline on community acquired pneumonia (CAP) determined that complex phase cannot be used to decide whether to begin or pause medications in CAP patients ${ }^{61}$. The IDSA guideline performed wide literature reviews to evaluate the additional benefit of utilising procalcitonin, CRP, or the Updated Clinical Pulmonary Infection Index with clinical criteria for the evaluation of Hospital Acquired Pneumonia (HAP) or Ventilator Associated Pneumonia (VAP) ${ }^{33}$.

\section{COVID-19 ASSOCIATED WITH CO-INFECTIONS:}

Patients having lung viral infections are more likely to develop subsequent bacterial infections, which lead to higher disease severity and death ${ }^{62}$. COVID-19 has a wide range of illness severity, including symptomless and non-specific flulike illness to pneumonia and life-threatening consequences such acute respiratory distress syndrome (ARDS) and multiple organ failure63. Furthermore, recurrent bacterial infections have been shown to be a substantial risk factor for poor COVID-19 results. Despite their demonstrated role in the complexity of respiratory disease symptoms, coinfections go unexplored during big pandemics of respiratory illnesses ${ }^{62}$. A meta-analysis and systemic review found 24 papers concentrating on microbial coinfections in hospitalized COVID-19 patients, revealing that 3.5 percent of patients suffered coinfections and 14.3 percent of COVID-19 patients had secondary infection, with total bacterial infection 6.9 percent. Another meta-analysis and systemic review that also included 30 papers assessing coinfections with COVID-19 patients found similar results, reporting that $7 \%$ of the patients had bacterial coinfections ${ }^{64}$. COVID-19 patients had a wide range of co-infections, range from no coinfections to 100 percent coinfections in patients who died, as well as a wide range of antibiotic usage by chronic infection, ranging from 20 percent to 100 percent for antibiotics 65 . The results of a retrospective mono centre investigation done in France indicated an incidence of 28 percent bacterial coinfections in individuals with severe SARS-CoV-2, and the investigators strongly recommended systemic empirical antimicrobial treatment with third generation cephalosporin's. The majority of the bacterial coinfections found in their investigation were caused by methicillin-sensitive Staphylococcus aureus, Haemophilus influenzae, Streptococcus pneumoniae, and Enterobacteriaceae ${ }^{61}$.

\section{ANTIBIOTIC RESISTANCE RESEARCH AND HEALTH-CARE SYSTEM PRIORITY:}

\section{Diagnostics:}

COVID-19 has emphasised both the capabilities and confines of diagnostic technology; whereas analytical logistics with built-in redundancy have been successfully scaled up in many situations, we are still battling to identify SARS-CoV-2 infection accurately and quickly internationally. Moving forward, the AMR community should leverage on the investment in diagnostic logistics and adapt their usage for quick detection of both the causal agent of illness and any associated medication resistance, particularly in low- and middle-income countries (LMICs). In Ghana, for example, capacity building (both laboratory and staff) is required to address COVID-19 surveillance as well as guiding antibiotic dosing66. The AMR sector could encourage the present impetus to build and make widely available a low-cost, accurate, and fast-acting diagnostic for viral infections, such as the ACT Accelerator Diagnostics Partnership. Differentiating between bacterial and viral infections and swiftly identifying resistance carriers will not only minimize excessive antibiotic treatment and, as a result, the formation of $\mathrm{AMR}^{67}$.

\section{Monitoring:}

COVID-19 has yet again underscored the need of strengthening, open access, and continuous data gathering for infectious illnesses. This is especially crucial in the case of AMR, which frequently depends on passive surveillance: The WHO's GLASS programme is transitioning to active monitoring, although for the time being, convenience samples of isolates sent for phenotypic resistance testing are being collected. This means that they are more likely to sample people who have complicated, long-lasting diseases caused by resistant microorganisms. Global AMR observation is further complicated by significant breaks, particularly in 
developing nations ${ }^{68}$. New measures developed and deployed for COVID-19 might possibly be used to strengthen AMR environmental monitoring. For example, waste water surveillance might be utilized to identify alterations in COVID-19 and ARO occurrence as well as antibiotic concentrations early on 69 .

\section{HEALTH SYSTEM STRENGTHENING:}

\section{Antibiotic Management and Administration in the face of the CoVid-19 Pandemic:}

COVID-19 has exposed several flaws in our health-care systems. To effectively address AMR, it is critical to promote appropriate medication adherence as part of antimicrobial stewardship ${ }^{38}$. The World Health Organization has advocated for a larger pandemic response that ensures the continuity of vital health care services and constant supply of safety guaranteed and inexpensive antimicrobials, especially antiretroviral and tuberculosis medications, and vaccinations ${ }^{67}$. Antimicrobial management refers to joint, synchronized programmes and interventions that promote the selection of the appropriate antimicrobial treatment regimen, comprising dose, length of treatment, and mode of administration, while minimizing undesired effects ${ }^{70}$. The fact that the primary goal of antimicrobial stewardship is to reduce the occurrence of AMR and drug-resistant illnesses in most cases, antimicrobial stewardship is primarily a behaviour change problem for healthcare personnel and healthcare organisations in advanced healthcare facilities. Antimicrobial stewardship in LMIC healthcare institutions is exacerbated by restricted access to drugs, worries about counterfeit medicines, and insufficient hospital infection prevention programme infrastructure ${ }^{71}$. In order to promote antimicrobial management, clinicians such as infectious disease doctors, nurses, clinical pharmacists, and other care providers should be committed. Hospitals with functioning infection prevention programs would try to engage antimicrobial prescription issues even when they are not clearly observable in their absence. They must also be involved in the formation of facility guidelines ${ }^{72,73}$. Before using antibiotics, a microbiological test should be done, and if the likelihood of bacterial superinfection is minimal, antibiotic treatment should be assessed and discontinued. Furthermore, as soon as it is comfortable, a transfer from intravenous to oral antibiotics should be investigated. Because of anecdotal evidence, azithromycin is being used on a regular basis antibiotics should be administered for the shortest amount of time feasible, and prophylactic antibiotics should be avoided. Despite the difficulty in distinguishing COVID-19 from bacterial pneumonia, the uncertainty about bacterial superinfections, the lack of particular antiviral therapy for the recent pandemic, and the increased rates of mortality, antibiotics as portion of the empiric treatment for the most intense suspected or confirmed COVID-19 cases (e.g., patients requiring mechanical ventilation) should not be overlooked. However, even during a pandemic, antibiotics should be taken with caution ${ }^{39}$.

\section{CONCLUSION:}

The widespread utilisation of antimicrobial drugs during the COVID-19 outbreak has raised the spectre of antimicrobial resistance. Even before the outbreak, developing nations were reporting significant levels of resistance. Several variables that are particular to developing world have acquired prominence during the COVID-19 pandemic. This teaches us a lot of things, one of which is that, medical improvements, humans are still extremely vulnerable to disease with limited or no traditional therapy. Immediately crucial components of any AMR mitigation approach are increased spending in education and increased public knowledge of AMR. Numerous studies into managing pathogens, as well as the creation of more functional antimicrobials, is required. Reserving antibiotic therapy for patients with the most severe COVID-19 illness and restricting antibiotic treatment to five days, as most recommendations, detailed observation investigation is now necessary to enhance COVID-19 patient care.

\section{Conflicts of Interest: No conflicts of interest.}

Funding Statement: This review did not receive any funding.

\section{REFERENCES:}

1. Rodriguez-Morales AJ, Bonilla-Aldana DK, Balbin-Ramon GJ, Rabaan AA, Sah R, Paniz-Mondolfi A, Pagliano P, Esposito S. History is repeating itself: Probable zoonotic spillover as the cause of the 2019 novel Coronavirus Epidemic. Infez Med. 2020; 28(1):3-5.

2. Gralinski LE, Menachery VD. Return of the Coronavirus: 2019 nCoV. Viruses. 2020; 12(2):135. https://doi.org/10.3390/v12020135.

3. Hoffmann M, Kleine-Weber H, Schroeder S, Krüger N, Herrler T, Erichsen S, Schiergens TS, Herrler G, Wu NH, Nitsche A, Müller MA, Drosten C, Pöhlmann S. SARS-CoV-2 Cell Entry Depends on ACE2 and TMPRSS2 and Is Blocked by a Clinically Proven Protease Inhibitor. Cell. 2020; 181(2):271-280.e8. https://doi.org/10.1016/j.cell.2020.02.052.

4. Fehr AR, Channappanavar R, Perlman S. Middle East Respiratory Syndrome: Emergence of a Pathogenic Human Coronavirus. Annu Rev Med. 201714; 68:387-399. https://doi.org/10.1146/annurev-med-051215-031152.

5. Shallcross LJ, Howard SJ, Fowler T, Davies SC. Tackling the threat of antimicrobial resistance: from policy to sustainable action. Philos Trans R Soc Lond B Biol Sci. 2015;370(1670):20140082. https://doi.org/10.1098/rstb.2014.0082.

6. Founou LL, Founou RC, Essack SY. Antibiotic Resistance in the Food Chain: A Developing Country-Perspective. Front Microbiol. 2016; 7:1881. https://doi.org/10.3389/fmicb.2016.01881.

7. Founou RC, Blocker AJ, Noubom M, et al. The COVID-19 pandemic: a threat to antimicrobial resistance containment. Future Sci OA. 2021; 7(8):FSO736. https://doi.org/10.2144/fsoa-2021-0012.

8. Rossolini GM, Arena F, Pecile P, Pollini S. Update on the antibiotic resistance crisis. Curr Opin Pharmacol. 2014; 18:5660. https://doi.org/10.1016/j.coph.2014.09.006.

9. Ventola CL. The antibiotic resistance crisis: part 1: causes and threats. P T. 2015; 40(4):277-83.

10. Vidovic N, Vidovic S. Antimicrobial Resistance and Food Animals: Influence of Livestock Environment on the Emergence and Dissemination of Antimicrobial Resistance. Antibiotics (Basel). 2020; 9(2):52. https://doi.org/10.3390/antibiotics9020052.

11. Beović $B$, Doušak $M$, Ferreira-Coimbra J, Nadrah $K$, Rubulotta $F$, Belliato M, Berger-Estilita J, Ayoade F, Rello J, Erdem H. Antibiotic use in patients with COVID-19: a 'snapshot' Infectious Diseases International Research Initiative (ID-IRI) survey. J Antimicrob Chemother. 2020; 75(11):3386-3390. https://doi.org/10.1093/jac/dkaa326.

12. Rezasoltani S, Yadegar A, Hatami B, Asadzadeh Aghdaei H, Zali MR. Antimicrobial Resistance as a Hidden Menace Lurking Behind the COVID-19 Outbreak: The Global Impacts of Too Much Hygiene on AMR. Front Microbiol. 2020; 11:590683. https://doi.org/10.3389/fmicb.2020.590683.

13. Singh S, Rehman S, Fatima Z, Hameed S. Protein kinases as potential anticandidal drug targets. Front Biosci (Landmark Ed). 2020; 25:1412-1432. https://doi.org/10.2741/4862. 
14. EU. Antimicrobial resistance. European Commission; 2017 http://ec.europa.eu/dgs/health food-safety/amr/index en.htm.

15. Mossialos E, Morel C, Edwards S, Berenson J, Gemmill-Toyama M, Brogan D. Policies and incentives for promoting innovation in antibiotic research. Copenhagen: World Health Organization; 2010.

16. David KB, Adebisi YA. Proposed model for hospital and community pharmacy services during COVID-19 pandemic in Nigeria. Int $\quad J \quad$ Pharm Pract. 2020; 28(5):544-545. https://doi.org/10.1111/ijpp.12652.

17. Lucero-Prisno D, Adebisi Y, Lin X. Current efforts and challenges facing responses to 2019-nCoV in Africa. Glob Health Res Policy. 2020; 5(1). https://doi.org/10.1186/s41256-020-00148-1.

18. lein EY, Monteforte B, Gupta A, Jiang W, May L, Hsieh YH, Dugas A. The frequency of influenza and bacterial coinfection: a systematic review and meta-analysis. Influenza Other Respir Viruses. 2016; 10(5):394-403. https://doi.org/10.1111/irv.12398.

19. Holubar M. Antimicrobial resistance: a global public health emergency further exacerbated by international travel. J Travel Med. $2020 \quad$ Feb 3; 27(1):taz095 https://doi.org/10.1093/jtm/taz095.

20. Rasheed F, Saeed M, Alikhan NF, Baker D, Khurshid M, Ainsworth EV, Turner AK, Imran AA, Rasool MH, Saqalein M, Nisar MA, Fayyaz Ur Rehman M, Wain J, Yasir M, Langridge GC, Ikram A. Emergence of Resistance to Fluoroquinolones and Third-Generation Cephalosporins in Salmonella Typhi in Lahore, Pakistan. Microorganisms. 2020; 8(9):1336 https://doi.org/10.3390/microorganisms8091336.

21. Langford BJ, So M, Raybardhan S, Leung V, Westwood D, MacFadden DR, Soucy JR, Daneman N. Bacterial co-infection and secondary infection in patients with COVID-19: a living rapid review and meta-analysis. Clin Microbiol Infect. 2020; 26(12):1622-1629. https://doi.org/10.1016/j.cmi.2020.07.016.

22. Michael CA, Dominey-Howes D, Labbate M. The antimicrobial resistance crisis: causes, consequences, and management. Front Public Health. 2014; 2:145. https://doi.org/10.3389/fpubh.2014.00145.

23. Nothias LF, Knight R, Dorrestein PC. Antibiotic discovery is a walk in the park. Proc Natl Acad Sci U S A. 2016; 113(51):1447714479. https://doi.org/10.1073/pnas.1618221114.

24. Nelson N, Joshi M, Kirika R. Antimicrobial resistance: the need for action in the East, Central and Southern Africa Region, submitted to the US agency for international development by the strengthening pharmaceutical systems (SPS) program. Arlington, VA: Management Sciences for Health; 2009.

25. Davies J, Davies D. Origins and evolution of antibiotic resistance. Microbiol Mol Biol Rev. 2010; 74(3):417-433. https://doi.org/10.1128/MMBR.00016-10.

26. Knight GM, Glover RE, McQuaid CF, Olaru ID, Gallandat K, Leclerc QJ, Fuller NM, Willcocks SJ, Hasan R, van Kleef E, Chandler CI. Antimicrobial resistance and COVID-19: Intersections and implications. $\quad$ Elife. 2021; 10:e64139. https://doi.org/10.7554/eLife.64139.

27. Benmerzouga I, Al-Zammay SA, Al-Shammari MM, Alsaif SA, Alhaidan TM, Aljofan M. Practices of patients consuming antibiotics and knowledge about antibiotic resistance in Hail region - Saudi Arabia. Future Sci OA. 2019; 5(10):FSO420. https://doi.org/10.2144/fsoa-2019-0054.

28. Ganguly NK, Arora NK, Chandy SJ, Fairoze MN, Gill JP, Gupta U, Hossain S, Joglekar S, Joshi PC, Kakkar M, Kotwani A, Rattan A, Sudarshan H, Thomas K, Wattal C, Easton A, Laxminarayan R; Global Antibiotic Resistance Partnership (GARP) - India Working Group. Rationalizing antibiotic use to limit antibiotic resistance in India. Indian J Med Res. 2011; 134(3):281-94.

29. Nayyar GML, Attaran A, Clark JP, et al. Responding to the pandemic of falsified medicines. Am J Trop Med Hyg. 2015; 92(6 Suppl):113-118. https://doi.org/10.4269/ajtmh.14-0393.
30. Gill K. A primary evaluation of service delivery under the National Rural Health Mission (NRHM): findings from a study in Andhra Pradesh, Uttar Pradesh, Bihar and Rajasthan. Planning Commission of India, Government of India; 2009

31. WBG. Drug-resistant infections. A threat to our economic future World Bank Group; 2016.

32. Boolchandani M, D'Souza AW, Dantas G. Sequencing-based methods and resources to study antimicrobial resistance. Nat Rev Genet. 2019; 20(6):356-370. https://doi.org/10.1038/s41576-019-0108-4.

33. Xu XW, Wu XX, Jiang XG, Xu KJ, Ying LJ, Ma CL, Li SB, Wang HY, Zhang S, Gao HN, Sheng JF, Cai HL, Qiu YQ, Li LJ. Clinical findings in a group of patients infected with the 2019 novel coronavirus (SARS-Cov-2) outside of Wuhan, China: retrospective case series. BMJ. 2020; 368:m606. https://doi.org/10.1136/bmj.m606.

34. Huang C, Wang Y, Li X, Ren L, Zhao J, Hu Y et al. Clinical features of patients infected with 2019 novel coronavirus in Wuhan, China. The Lancet. 2020; 395(10223):497-506. https://doi.org/10.1016/S0140-6736(20)30183-5.

35. Chen N, Zhou M, Dong X, Qu J, Gong F, Han Y, Qiu Y, Wang J, Liu Y, Wei Y, Xia J, Yu T, Zhang X, Zhang L. Epidemiological and clinical characteristics of 99 cases of 2019 novel coronavirus pneumonia in Wuhan, China: a descriptive study. Lancet. 2020; 395(10223):507-513. https://doi.org/10.1016/S01406736(20)30211-7.

36. Ruiz J. Enhanced antibiotic resistance as a collateral COVID-19 pandemic effect?.J Hosp Infect. 2021; 107:114-115. https://doi.org/10.1016/j.jhin.2020.11.010.

37. Zhou F, Yu T, Du R, Fan G, Liu Y, Liu Z, Xiang J, Wang Y, Song B, Gu X, Guan L, Wei Y, Li H, Wu X, Xu J, Tu S, Zhang Y, Chen H, Cao B. Clinical course and risk factors for mortality of adult inpatients with COVID-19 in Wuhan, China: a retrospective cohort study. Lancet. 2020 Mar 28; 395(10229):1054-1062. https://doi.org/10.1016/S0140-6736(20)30566-3.

38. Rawson TM, Moore LSP, Castro-Sanchez E, Charani E, Davies F, Satta G, Ellington MJ, Holmes AH. COVID-19 and the potential long-term impact on antimicrobial resistance. J Antimicrob Chemother. 2020; 75(7):1681-1684 https://doi.org/10.1093/jac/dkaa194.

39. Huttner BD, Catho G, Pano-Pardo JR, Pulcini C, Schouten J. COVID-19: don't neglect antimicrobial stewardship principles! Clin Microbiol Infect. 2020 Jul; 26(7):808-810. https://doi.org/10.1016/j.cmi.2020.04.024.

40. Huang Q, Deng X, Li Y, Sun X, Chen Q, Xie M, Liu S, Qu H, Liu S, Wang L, He G, Gong Z. Clinical characteristics and drug therapies in patients with the common-type coronavirus disease 2019 in Hunan, China. Int J Clin Pharm. 2020 Jun; 42(3):837-845. https://doi.org/10.1007/s11096-020-01031-2.

41. Zavala-Flores E, Salcedo-Matienzo J. Medicación prehospitalaria en pacientes hospitalizados por COVID-19 en un hospital público de Lima-Perú. Acta Med Peru. 2020; 37. https://doi.org/org/10.35663/amp.2020.373.1277.

42. Firth A, Prathapan P. Azithromycin: The First Broad-spectrum Therapeutic. Eur J Med Chem. 2020; 207:112739. https://doi.org/10.1016/j.ejmech.2020.112739.

43. Gautret P, Lagier IC, Parola P, Hoang VT, Meddeb L, Mailhe M Doudier B, Courjon J, Giordanengo V, Vieira VE, Tissot Dupont H, Honoré S, Colson P, Chabrière E, La Scola B, Rolain JM, Brouqui P, Raoult D. Hydroxychloroquine and azithromycin as a treatment of COVID-19: results of an open-label non-randomized clinical trial. Int J Antimicrob Agents. 2020; 56(1):105949. https://doi.org/10.1016/j.ijantimicag.2020.

44. Clancy CJ, Schwartz IS, Kula B, Nguyen MH. Bacterial Superinfections Among Persons With Coronavirus Disease 2019: A Comprehensive Review of Data From Postmortem Studies. Open Forum Infect Dis. 2021; 8(3):ofab065. https://doi.org/10.1093/ofid/ofab065.

45. He Y, Li W, Wang Z, Chen H, Tian L, Liu D. Nosocomial infection among patients with COVID-19: A retrospective data analysis of 
918 cases from a single center in Wuhan, China. Infect Control Hosp Epidemiol. 2020; 41(8):982-983. https://doi.org/10.1017/ice.2020.126.

46. Rawson TM, Moore LSP, Zhu N, Ranganathan N, Skolimowska K Gilchrist M, Satta G, Cooke G, Holmes A. Bacterial and Fungal Coinfection in Individuals With Coronavirus: A Rapid Review To Support COVID-19 Antimicrobial Prescribing. Clin Infect Dis. 2020; 71(9):2459-2468. https://doi.org/10.1093/cid/ciaa530.

47. Manohar P, Loh B, Athira S, et al. Secondary Bacterial Infections During Pulmonary Viral Disease: Phage Therapeutics as Alternatives to Antibiotics?. Front Microbiol. 2020; 11:1434. https://doi.org/10.3389/fmicb.2020.01434.

48. Wang L, He W, Yu X, Hu D, Bao M, Liu H, Zhou J, Jiang H. Coronavirus disease 2019 in elderly patients: Characteristics and prognostic factors based on 4-week follow-up. J Infect. 2020 Jun; 80(6):639-645. https://doi.org/10.1016/j.jinf.2020.03.019.

49. Kim D, Quinn J, Pinsky B, Shah NH, Brown I. Rates of Co-infection Between SARS-CoV-2 and Other Respiratory Pathogens. JAMA. 2020 May 26; 323(20):2085-2086 https://doi.org/10.1001/jama.2020.6266.

50. Mack I, Sharland M, Berkley JA, Klein N, Malhotra-Kumar S Bielicki J. Antimicrobial Resistance Following Azithromycin Mass Drug Administration: Potential Surveillance Strategies to Assess Public Health Impact. Clin Infect Dis. 2020; 70(7):15011508. https://doi.org/10.1093/cid/ciz893.

51. Rainsford KD, Parke AL, Clifford-Rashotte M, Kean WF. Therapy and pharmacological properties of hydroxychloroquine and chloroquine in treatment of systemic lupus erythematosus, rheumatoid arthritis and related diseases.

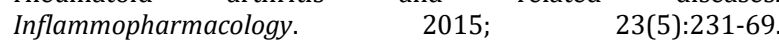
https://doi.org/10.1007/s10787-015-0239-y.

52. Arastehfar A, Carvalho A, Nguyen MH, et al. COVID-19Associated Candidiasis (CAC): An Underestimated Complication in the Absence of Immunological Predispositions?.J Fungi (Basel). 2020; 6(4):211. https://doi.org/10.3390/jof6040211.

53. Chowdhary A, Sharma A. The lurking scourge of multidrug resistant Candida auris in times of COVID-19 pandemic. J Glob Antimicrob Resist. 2020; 22:175-176. https://doi.org/10.1016/j.jgar.2020.06.003.

54. Porretta AD, Baggiani A, Arzilli G, et al. Increased Risk of Acquisition of New Delhi Metallo-Beta-Lactamase-Producing Carbapenem-Resistant Enterobacterales (NDM-CRE) among a Cohort of COVID-19 Patients in a Teaching Hospital in Tuscany, Italy. Pathogens. 2020; 9(8):635. https://doi.org/10.3390/pathogens9080635.

55. Cantón R, Gijón D, Ruiz-Garbajosa P. Antimicrobial resistance in ICUs: an update in the light of the COVID-19 pandemic. Curr Opin Crit Care. 2020; 26(5):433-441. https://doi.org/10.1097/MCC.0000000000000755.

56. Gomez-Simmonds A, Annavajhala MK, McConville TH, Dietz DE, Shoucri SM, Laracy JC, Rozenberg FD, Nelson B, Greendyke WG, Furuya EY, Whittier S, Uhlemann AC. Carbapenemase-producing Enterobacterales causing secondary infections during the COVID-19 crisis at a New York City hospital. J Antimicrob $\begin{array}{lll}\text { Chemother. } & \text { 2021; } & \end{array}$ https://doi.org/10.1093/jac/dkaa466.

57. Fattorini L, Creti R, Palma C, Pantosti A. Bacterial coinfections in COVID-19: an underestimated adversary. Annali dell'Istituto superiore di sanita. 2020; 56(3):359-64.

58. Sermo, Breaking results: Sermo's COVID-19 real time barometer study WAVE I: March 25-27, (n.d.).

https://publiccdn.sermo.com/covid19/c8/be4e/4edbd4/dbd4ba4a c5a3b3d9a479f99cc5/wave-i-sermo-covid-19-global-analysisfinal. pdf.
59. Baron SA, Devaux C, Colson P, Raoult D, Rolain JM. Teicoplanin: an alternative drug for the treatment of COVID-19?. Int J Antimicrob Agents. 2020; 55(4):105944. https://doi.org/10.1016/j.ijantimicag.2020.105944.

60. Antimicrobial resistance in the age of COVID-19. Nat Microbiol 2020; 5(6):779. https://doi.org/10.1038/s41564-020-0739-4.

61. Contou D, Claudinon A, Pajot O, Micaëlo M, Longuet Flandre P, Dubert M, Cally R, Logre E, Fraissé M, Mentec H, Plantefève G. Bacterial and viral co-infections in patients with severe SARS CoV-2 pneumonia admitted to a French ICU. Ann Intensive Care. 2020; 10(1):119. https://doi.org/10.1186/s13613-020-00736

62. Cox MJ, Loman N, Bogaert D, O'Grady J. Co-infections: potentially lethal and unexplored in COVID-19. Lancet Microbe. 2020; 1(1):e11. https://doi.org/10.1016/S2666-5247(20)30009-4.

63. Zafer MM, El-Mahallawy HA, Ashour HM. Severe COVID-19 and Sepsis: Immune Pathogenesis and Laboratory Markers. $\begin{array}{llll}\text { Microorganisms. } & 2021 & \text { J; } & \text { 9(1):159. }\end{array}$ https://doi.org/10.3390/microorganisms9010159.

64. Lansbury L, Lim B, Baskaran V, Lim WS. Co-infections in people with COVID-19: a systematic review and meta-analysis. J Infect 2020; 81(2):266-275. https://doi.org/10.1016/j.jinf.2020.05.046.

65. Clancy CJ, Nguyen MH. Coronavirus Disease 2019, Superinfections, and Antimicrobial Development: What Can We Expect? Clin Infect Dis. 2020; 71(10):2736-2743. https://doi.org/10.1093/cid/ciaa524.

66. Egyir B, Obeng-Nkrumah N, Kyei GB. COVID-19 pandemic and antimicrobial resistance: Another call to strengthen laboratory diagnostic capacity in Africa. Afr J Lab Med. 2020; 9(1):1302. https://doi.org/10.4102/ajlm.v9i1.1302.

67. Getahun H, Smith I, Trivedi K, Paulin S, Balkhy HH. Tackling antimicrobial resistance in the COVID-19 pandemic. Bull World Health Organ. 2020; 98(7):442-442A https://doi.org/10.2471/BLT.20.268573.

68. Seale AC, Gordon NC, Islam J, Peacock SJ, Scott JAG. AMR Surveillance in low and middle-income settings - A roadmap for participation in the Global Antimicrobial Surveillance System (GLASS). Wellcome Open Res. 2017; 2:92. https://doi.org/10.12688/wellcomeopenres.12527.1.

69. Bivins A, North D, Ahmad A, Ahmed W, Alm E, Been F et al Wastewater-Based Epidemiology: Global Collaborative to Maximize Contributions in the Fight Against COVID-19. Environmental Science \& Technology. 2020; 54(13):7754-7757. https://doi.org/10.1021/acs.est.0c02388.

70. Fishman N. Society for Healthcare Epidemiology of America, Infectious Diseases Society ofAmerica, Pediatric Infectious Diseases Society, Policy Statement on Antimicrobial Stewardship by the Society for Healthcare Epidemiology of America (SHEA), the Infectious Diseases Society of America (IDSA), and the Pediatric Infectious Diseases Society (PIDS). Infect Control Hosp Epidemiol. 2012; 33:322-7. https://doi.org/10.1086/665010.

71. Stevens MP, Patel PK, Nori P. Involving antimicrobial stewardship programs in COVID-19 response efforts: All hands on deck. Infect Control Hosp Epidemiol. 2020; 41(6):744-745. https://doi.org/10.1017/ice.2020.69.

72. Jones KA, Watson M, Jacob JT, Wiley Z. Antimicrobial stewardship interventions to minimize healthcare worker exposure to SARS-CoV-2. Infect Control Hosp Epidemiol. 2021; 42(5):645-646. https://doi.org/10.1017/ice.2020.302.

73. Velasco-Arnaiz E, López-Ramos MG, Simó-Nebot S, Jordan I, Ríos-Barnés M, Urrea-Ayala M, Monsonís M, Fortuny C, NogueraJulian A; Kids Corona project. Pediatric antimicrobial stewardship in the COVID-19 outbreak. Infect Control Hosp Epidemiol. 2021; 42(5):642-644. https://doi.org/10.1017/ice.2020.312. 